\title{
Article \\ A Sustainable Technique to Prepare High-Purity Vanadium Pentoxide via Purification with Low Ammonium Consumption
}

\author{
Guoce Lin $1,2,3,4$, Jing Huang $1,2,3,4, *$, Yimin Zhang $1,2,3,4$ and Pengcheng $\mathrm{Hu}$ 1,2,3,4 \\ 1 School of Resource and Environmental Engineering, Wuhan University of Science and Technology, \\ Wuhan 430081, China; guocelin@163.com (G.L.); zym126135@126.com (Y.Z.); hpcmy126@126.com (P.H.) \\ 2 State Environmental Protection Key Laboratory of Mineral Metallurgical Resources Utilization and Pollution \\ Control, Wuhan 430081, China \\ 3 Collaborative Innovation Center of Strategic Vanadium Resources Utilization, Wuhan 430081, China \\ 4 Hubei Provincial Engineering Technology Research Center of Highly Efficient Cleaning Utilization for Shale \\ Vanadium Resource, Wuhan 430081, China \\ * Correspondence: crystal208@126.com
}

check for updates

Citation: Lin, G.; Huang, J.; Zhang, Y.; Hu, P. A Sustainable Technique to Prepare High-Purity Vanadium Pentoxide via Purification with Low Ammonium Consumption. Materials 2022, 15, 1945. https://doi.org/ $10.3390 / \mathrm{ma} 15051945$

Received: 20 January 2022

Accepted: 2 March 2022

Published: 5 March 2022

Publisher's Note: MDPI stays neutral with regard to jurisdictional claims in published maps and institutional affiliations.

Copyright: (C) 2022 by the authors. Licensee MDPI, Basel, Switzerland. This article is an open access article distributed under the terms and conditions of the Creative Commons Attribution (CC BY) license (https:// creativecommons.org/licenses/by/ $4.0 /)$.

\begin{abstract}
The general preparation method for $\mathrm{V}_{2} \mathrm{O}_{5}$ is ammonium salt vanadium precipitation, which inevitably produces large amounts of ammonia nitrogen wastewater. In this paper, we propose an environmentally friendly method for preparing high-purity $\mathrm{V}_{2} \mathrm{O}_{5}$ with low ammonium consumption. The purity of the $\mathrm{V}_{2} \mathrm{O}_{5}$ product reaches more than $99 \%$ while reducing the level of ammonium consumption. The vanadium precipitation efficiency reaches $99.23 \%$ and the $\mathrm{V}_{2} \mathrm{O}_{5}$ purity of the product reaches $99.05 \%$ under the following conditions: precipitation time of $1.5 \mathrm{~h}$, precipitation temperature of $98^{\circ} \mathrm{C}$, initial precipitation $\mathrm{pH}$ of 2 , ammonium addition coefficient of 2 , purification time of 5 min with purification performed twice, purification temperature of $65^{\circ} \mathrm{C}$. In this study, compared with the use of ammonia spirit for vanadium precipitation and ammonium salt vanadium precipitation, the ammonia consumption levels are reduced by $79.80 \%$ and $80.00 \%$, and the purity levels are increased by $0.70 \%$ and $1.01 \%$, respectively. The compositions of the precipitated $\left(\mathrm{NaV}_{3} \mathrm{O}_{8} \cdot \mathrm{xH}_{2} \mathrm{O}\right)$ and purified $\left(\left(\mathrm{NH}_{4}\right)_{2} \mathrm{~V}_{6} \mathrm{O}_{16} \cdot 1.5 \mathrm{H}_{2} \mathrm{O}\right)$ hydrolysis products are characterized via $\mathrm{XRD}$. The TGA results show that $\mathrm{NaV}_{3} \mathrm{O}_{8} \cdot \mathrm{xH}_{2} \mathrm{O}$ contains 1.5 times the amount of crystal water. The FTIR results explain that the two $\mathrm{V}_{3} \mathrm{O}_{8}{ }^{-}$layers are combined end-to-end to form a $\mathrm{V}_{6} \mathrm{O}_{16}{ }^{2-}$ layer. The change of the product image indicates that the purification process includes three stages. Firstly, heating and $\mathrm{NH}_{4}{ }^{+}$attack expand the $\mathrm{V}_{3} \mathrm{O}_{8}{ }^{-}$layer. $\mathrm{NH}^{+}$diffuses more easily into the $\mathrm{V}_{3} \mathrm{O}_{8}{ }^{-}$ layer. Secondly, $\mathrm{NH}_{4}{ }^{+}$destroys the electrostatic interaction between $\mathrm{Na}^{+}$with the $\mathrm{V}_{3} \mathrm{O}_{8}{ }^{-}$layer and replacing $\mathrm{Na}^{+}$. Finally, $\mathrm{V}_{3} \mathrm{O}_{8}{ }^{-}$is polymerized into $\mathrm{V}_{6} \mathrm{O}_{16}{ }^{2-}$ to keep the crystal structure stable.
\end{abstract}

Keywords: $\mathrm{V}_{2} \mathrm{O}_{5}$; vanadium precipitation; replacement; purification

\section{Introduction}

Vanadium is a strategic reserve resource [1]. Vanadium pentoxide is one of the most important oxides of vanadium [2], which is a layered amphoteric oxide with good catalytic activity [3]. $\mathrm{V}_{2} \mathrm{O}_{5}$ is widely used in vanadium batteries and electrode materials, nanostructured materials, and optical devices, as well as in metallurgy and the chemical and aerospace industries, owing to its excellent physical and chemical properties [4-9]. Due to the widespread application of vanadium pentoxide, its demand and purity requirements are higher. As such, the clean and efficient preparation of high-purity vanadium pentoxide has attracted widespread attention [10].

The vanadium precipitation process is an important step in obtaining vanadium products using vanadium shale extraction technology, which mainly uses the different stability levels of vanadium and impurity ions in the same solution to separate vanadium and impurity ions to obtain high-purity vanadium products [11]. The general process of vanadium precipitation mainly includes hydrolyzed vanadium precipitation, ammonium 
salt vanadium precipitation, ferric salt vanadium precipitation, and calcium salt vanadium precipitation [12]. Ferric salt and calcium salt vanadium precipitation processes have a small application range and are mainly used to enrich the intermediate products of vanadium [13]. Ammonium salt vanadium precipitation has high efficiency and leads to high product purity [14]. Its ammonium consumption is generally about 8 [12]. However, ammonium salt as a precipitant inevitably produces a large amount of ammonia nitrogen wastewater and ammonia-containing waste gas, which causes a serious threat to the environment [15]. Hydrolyzed vanadium precipitation was widely used in early industrial production. Although the product of the hydrolyzed vanadium precipitation has low purity (around $85.00 \%$ ), the process results in low levels of environmental pollution and high production efficiency [14]. With the strengthening of environmental protection, the limitations of general vanadium precipitation technology, such as the small application range, low product purity, and environmental problems, seriously restrict the sustainable development of vanadium extraction technology. It is necessary to explore a clean and efficient production technology for $\mathrm{V}_{2} \mathrm{O}_{5}$.

In the process of hydrolyzed vanadium precipitation, the binding capacity of $\mathrm{Na}^{+}$ and polyvanadate ions is greater than that of $\mathrm{H}^{+}[11,14]$. Therefore, the vanadate and $\mathrm{Na}^{+}$ combine to form sodium polyvanadate and subsequently crystallize. The main reason for the low purity of the product is that a large amount of $\mathrm{Na}^{+}$is precipitated. In the process of ammonium salt vanadium precipitation, the binding capacity of $\mathrm{NH}_{4}{ }^{+}$with polyvanadate ion is better than that of $\mathrm{Na}^{+}$[12]. Therefore, ammonium polyvanadate crystals will be precipitated. Due to the different selectivity levels of polyvanadate to cations in the solution, the polyvanadate will precipitate and separate from the most stable structure. Based on this principle, a low-purity sodium polyvanadate precipitate was prepared through the hydrolytic vanadium precipitation process. Due to polyvanadate ion having different selectivity to $\mathrm{NH}_{4}{ }^{+}$and $\mathrm{Na}^{+}$, the replacement reaction of $\mathrm{Na}^{+}$with $\mathrm{NH}_{4}^{+}$may occur during the purification of sodium polyvanadate precipitate with ammonia salt [16]. Then, the high-purity $\mathrm{V}_{2} \mathrm{O}_{5}$ can be prepared by calcining the purified product at a high temperature.

The purpose of this research is to obtain a low-pollution, high-efficiency process by integrating the advantages of multiple vanadium precipitation processes. The combined process can be used to solve the limitations of general vanadium precipitation technologies and environmental problems caused by ammonia nitrogen, and to promote the green development of the vanadium extraction process.

\section{Experimental}

\subsection{Materials}

In this study, all chemical reagents were of analytical grade. All solutions were prepared with deionized water. Vanadium in vanadium-rich liquid is tetravalent. $\mathrm{NaClO}_{3}$ as an oxidant oxidizes $\mathrm{V}(\mathrm{IV})$ in the vanadium-rich liquid to $\mathrm{V}(\mathrm{V}) . \mathrm{Na}_{2} \mathrm{CO}_{3}$ (Sinopharm Chemical Reagent Co., Ltd, Shanghai, China) was used to adjust the $\mathrm{pH}$ of the vanadiumrich solution and ammonium chloride (Sinopharm Chemical Reagent Co., Ltd, China) was used as a detergent. The vanadium-rich liquid in this study was a stripping liquid obtained from vanadium shale (Tongshan, China) through roasting, acid leaching, extraction with D2EHPA (Sinopharm Chemical Reagent Co., Ltd, China), and stripping back extraction with sulfuric acid. Its composition is shown in Table 1 . The $\mathrm{pH}$ of vanadium-rich liquid was -0.16 , as measured using a pH S-3 acidity meter from Shanghai Lida Instrument Factory (Shanghai, China).

Table 1. Chemical composition of the vanadium-rich liquid (g/L).

\begin{tabular}{ccccccccccc}
\hline Element & $\mathbf{V}$ & $\mathbf{K}$ & $\mathbf{C a}$ & $\mathbf{N a}$ & $\mathbf{M g}$ & $\mathbf{A l}$ & $\mathbf{S i}$ & $\mathbf{P}$ & $\mathbf{A s}$ & $\mathbf{F e}$ \\
\hline Content & 42.27 & 0.37 & 0.44 & 0.42 & 0.08 & 8.80 & 0.26 & 0.48 & 0.37 & 0.12 \\
\hline
\end{tabular}




\subsection{Experimental Steps}

The process of hydrolytic vanadium precipitation-purification with ammonium salt is shown in Figure 1.

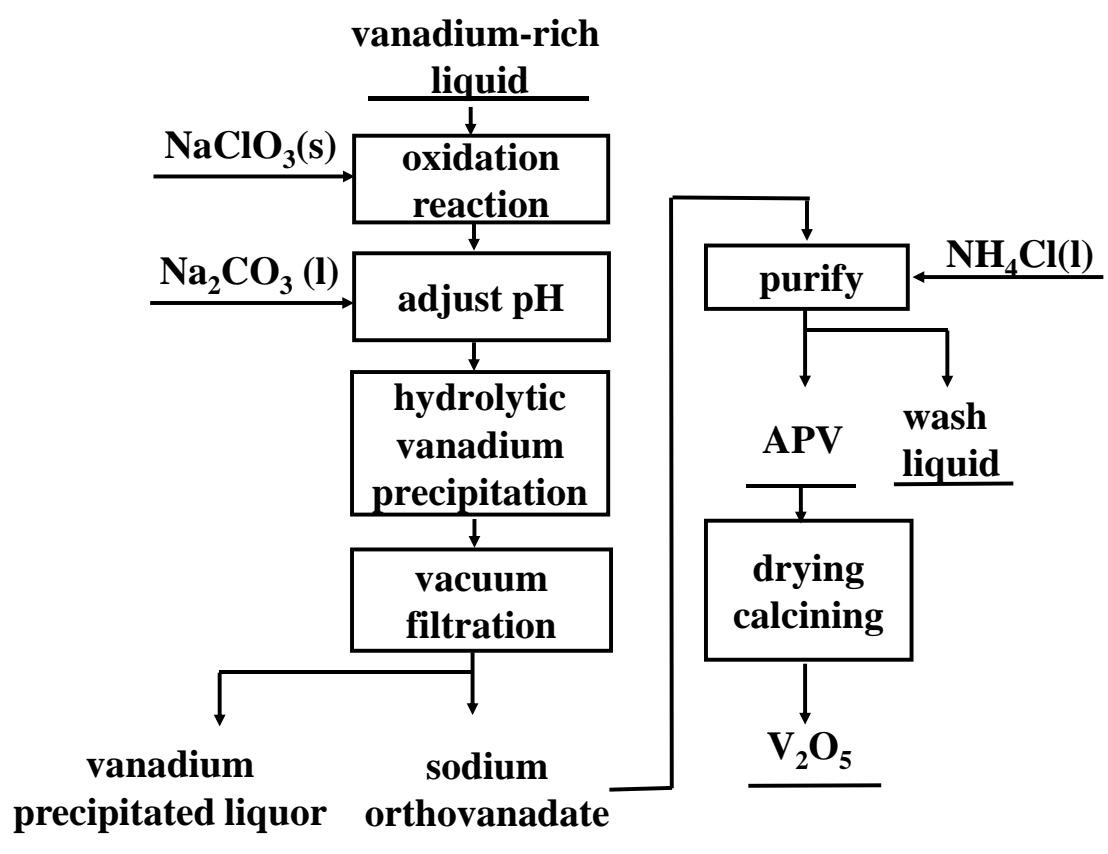

Figure 1. A flow chart of hydrolyzed vanadium precipitation-purification process with ammonium salt.

\subsubsection{Hydrolyzed Vanadium Precipitation}

The vanadium precipitation efficiency was determined by studying different influencing factors. The experiment was performed as follows. Firstly, $\mathrm{NaClO}_{3}$ was added into $30 \mathrm{~mL}$ vanadium-rich solution and heated in a water bath to $60^{\circ} \mathrm{C}$ for oxidation until the $\mathrm{V}^{4+}$ fully oxidized to $\mathrm{V}^{5+}$. Secondly, the $\mathrm{pH}$ of vanadium-rich liquid after oxidation was adjusted using sodium carbonate until it was suitable for vanadium precipitation, then heating and stirring were performed for a period. Finally, the vanadium precipitation and vanadium precipitation liquor were obtained by solid-liquid separation.

The precipitation efficiency $(\eta)$ of vanadium was calculated using the following Equation (1):

$$
\eta=1-\frac{\mathrm{C}_{\mathrm{b}} \mathrm{V}_{\mathrm{b}}}{\mathrm{C}_{\mathrm{a}} \mathrm{V}_{\mathrm{a}}} \times 100 \%
$$

where $C_{a}, C_{b}$ refer to the vanadium concentrations of vanadium-rich liquid and residual liquid $(\mathrm{g} / \mathrm{L})$, respectively; $\mathrm{V}_{\mathrm{a}}, \mathrm{V}_{\mathrm{b}}$ refer to the volumes of vanadium-rich liquid and residual liquid (L), respectively.

\subsubsection{Ammonium Salt Purification}

High-purity vanadium pentoxide was obtained by adjusting the influence of the type and amount of detergent, purification time, purification temperature, and other factors on the purification of the hydrolyzed vanadium product. The specific steps of the purification process were as follows. The ammonium chloride solution with a concentration of $20 \mathrm{~g} / \mathrm{L}$ was mixed with the hydrolyzed vanadium precipitation product and fully stirred at $450 \mathrm{r} / \mathrm{min}$. The purification process was performed with different ammonium addition coefficients (K), purification frequencies, purification temperatures, and purification times. The purification product was obtained via vacuum filtration after the reaction finished. The product of $\mathrm{V}_{2} \mathrm{O}_{5}$ was calcimined using the purified product at $520^{\circ} \mathrm{C}$ for $30 \mathrm{~min}$. 
The ammonium addition coefficient $\mathrm{K}$ was defined as the ratio of the amount of ammonium ions to the amount of $\mathrm{V}_{2} \mathrm{O}_{5}$ substance in the vanadium-rich liquid. The calculation formula for $\mathrm{K}$ was the same as Equation (2):

$$
\mathrm{K}=\frac{\mathrm{n}\left(\mathrm{NH}_{4}^{+}\right)}{\mathrm{n}\left(\mathrm{V}_{2} \mathrm{O}_{5}\right)}
$$

\section{Characterizations and Analysis}

In the study, the vanadium concentration in the vanadium precipitation liquor was measured via ferrous ammonium sulfate titration. The phase composition of the vanadium product was analyzed using an X-ray diffractometer (XRD, D/MAX-RB, Rigaku, Tokyo, Japan) equipped with $\mathrm{Cu} \mathrm{K} \alpha$ radiation $(\lambda=0.15406 \mathrm{~nm}, 40 \mathrm{KV}$ and $40 \mathrm{KA})$. Changes in chemical bonds during the reaction were recorded through the Fourier transform infrared (FTIR) spectra (Thermo Fisher Scientific Co., Waltham, MA, USA). The purity of $\mathrm{V}_{2} \mathrm{O}_{5}$ in the product was measured according to YB/T 5328-2009. The chemical element composition in the vanadium pentoxide product was determined by X-ray fluorescence spectrometer (XRF, Netherland PANalytical B.V., AXIOS, Almelo, The Netherlands). The content of crystal water in the product was conducted via thermogravimetric analysis (TG), using an STA449C integrated thermal analyzer from Germany Netzsch (Netzsch, Selb, Germany).

\section{Results and Discussion}

\subsection{Effects of Hydrolyzed Vanadium Precipitation Conditions on Precipitation Efficiency}

Figure 2A shows that the vanadium precipitation efficiency can be increased by extending the reaction time, although it does not increase significantly after $1.5 \mathrm{~h}$. This phenomenon indicates that the precipitation reaction reaches equilibrium after $1.5 \mathrm{~h}$. Considering the energy consumption and production efficiency, the optimal time was determined to be $1.5 \mathrm{~h}$ in the following experiment.

Figure 2B demonstrates that the temperature significantly influenced the vanadium precipitation efficiency. The hydrolysis of vanadium is difficult at low temperature. The higher the temperature, the more favorable the conditions for vanadium precipitation $[17,18]$. Due to temperature limitations under normal pressure, $98{ }^{\circ} \mathrm{C}$ was selected as the best temperature.

Figure 2C shows that the vanadium precipitation efficiency shows an upward trend due to the dissolution of sodium polyvanadate being reduced [14], and it shows a downward trend owing to the reaction of hydrolyzed vanadium precipitation being weakened [17]. The vanadium precipitation efficiency reaches the maximum value of $99.23 \%$ at the initial $\mathrm{pH}$ of 2 . Therefore, the optimal initial $\mathrm{pH}$ for hydrolyzed vanadium precipitation is 2 .

The main parameters of the vanadium hydrolysis precipitation process were studied to ensure that as many vanadium ions entered the hydrolysis vanadium precipitation solid product as possible, which is beneficial to the subsequent purification process to prepare more vanadium pentoxide products. Figure 2 reveals that the vanadium precipitation efficiency can reach $99.23 \%$ under the following conditions: time of $1.5 \mathrm{~h}$, temperature of $98^{\circ} \mathrm{C}$, initial $\mathrm{pH}$ of 2 . 

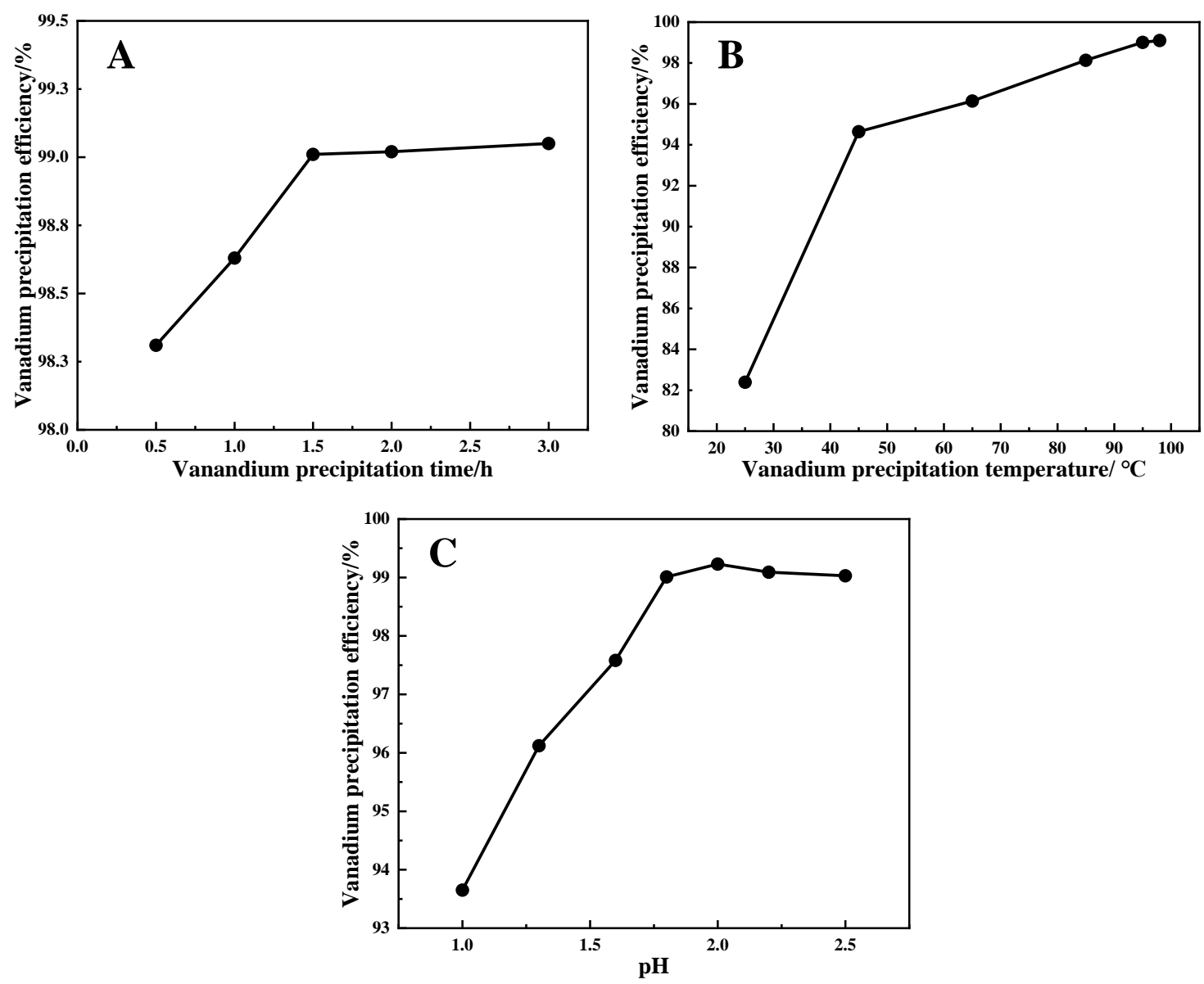

Figure 2. (A) Effect of time on the vanadium precipitation efficiency (operation conditions: initial $\mathrm{pH}$ of 1.8 , temperature of $95^{\circ} \mathrm{C}$ ). (B) Effect of temperature on the vanadium precipitation efficiency (operation conditions: initial $\mathrm{pH}$ of 1.8 , time of $1.5 \mathrm{~h}$ ). (C) Effect of the initial $\mathrm{pH}$ on vanadium precipitation efficiency (operation conditions: time of $1.5 \mathrm{~h}$, temperature of $98^{\circ} \mathrm{C}$ ).

\subsection{Ammonium Salt Purification}

\subsubsection{Effect of Detergent on Ammonium Salt Purification}

In this study, the main purpose of choosing ammonium salt as the detergent was to replace $\mathrm{Na}^{+}$with $\mathrm{NH}_{4}{ }^{+}$to improve the purity of the product. The general ammonium salts mainly include $\mathrm{NH}_{4} \mathrm{Cl},\left(\mathrm{NH}_{4}\right)_{2} \mathrm{SO}_{4}, \mathrm{NH}_{4} \mathrm{HCO}_{3}, \mathrm{NH}_{3} \cdot \mathrm{H}_{2} \mathrm{O}$, and $\left(\mathrm{NH}_{4}\right)_{2} \mathrm{CO}_{3}$. The production costs are high due to $\left(\mathrm{NH}_{4}\right)_{2} \mathrm{CO}_{3}$ being expensive. In addition, $\mathrm{NH}_{3} \cdot \mathrm{H}_{2} \mathrm{O}$ is volatile and inconvenient to store. $\mathrm{NH}_{3} \cdot \mathrm{H}_{2} \mathrm{O}$ and $\left(\mathrm{NH}_{4}\right)_{2} \mathrm{CO}_{3}$ are not suitable for actual industrial production. To find the best detergent, the effect of common ammonium salt as detergent on the purification process was studied. The experimental results are shown in the Figure 3.

The tests of the different ammonium salts as detergents were carried out under the following conditions: the temperature was $98^{\circ} \mathrm{C}$, the time was $1.5 \mathrm{~h}$, the initial $\mathrm{pH}$ was 2 , the ammonium addition coefficient was 2 , the purification temperature was $25^{\circ} \mathrm{C}$ with purification performed twice, and the purification time was $5 \mathrm{~min}$.

It can be seen from Figure 3 that when $\mathrm{NH}_{4} \mathrm{Cl},\left(\mathrm{NH}_{4}\right)_{2} \mathrm{SO}_{4}, \mathrm{NH}_{4} \mathrm{HCO}_{3}$, and $\mathrm{NH}_{3} \cdot \mathrm{H}_{2} \mathrm{O}$ were used as detergents, the $\mathrm{V}_{2} \mathrm{O}_{5}$ purity levels of the purified products were $98.50 \%$, $98.30 \%, 94.21 \%$, and $92.56 \%$, respectively. The low purity of the products when $\mathrm{NH}_{4} \mathrm{HCO}_{3}$ and $\mathrm{NH}_{3} \cdot \mathrm{H}_{2} \mathrm{O}$ were used as detergents was due to the alkaline solutions of $\mathrm{NH}_{4} \mathrm{HCO}_{3}$ and $\mathrm{NH}_{3} \cdot \mathrm{H}_{2} \mathrm{O}$, as the hydrolysis precipitation vanadium product (sodium polyvanadate) will dissolve into alkaline aqueous solution during the purification process. $\mathrm{Cl}^{-}$can promote the formation of sodium vanadate precipitation, and $\mathrm{SO}_{4}{ }^{2-}$ will inhibit the precipitation [10]. Therefore, compared with using ammonium sulfate as a detergent, the purity 
of the vanadium pentoxide product will be higher when ammonium chloride is used as a detergent for purification. The cost of $\mathrm{NH}_{4} \mathrm{Cl}$ was lower than other ammonium salts. Therefore, $\mathrm{NH}_{4} \mathrm{Cl}$ was the best detergent for the purification process.

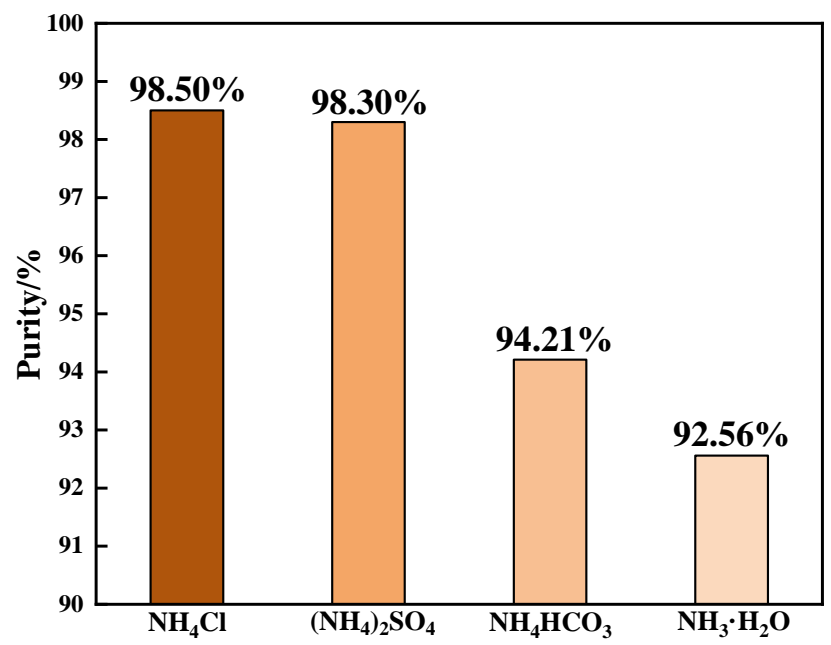

Figure 3. Effects of different detergents on ammonium salt purification (operation conditions: the precipitation temperature was $98^{\circ} \mathrm{C}$, the precipitation time was $1.5 \mathrm{~h}$, the initial $\mathrm{pH}$ was 2 , the ammonium addition coefficient was 2 , the purification temperature was $25^{\circ} \mathrm{C}$ with purification performed twice, and the purification time was $5 \mathrm{~min}$ ).

\subsubsection{Effect of Ammonium Addition Coefficient on Product Purity}

The main purpose of the purification process was to reduce ammonium consumption. The influence of different ammonium addition coefficients on the $\mathrm{V}_{2} \mathrm{O}_{5}$ purity of purification products was studied under the following conditions: purification temperature of $25^{\circ} \mathrm{C}$ with purification performed twice, purification time of $30 \mathrm{~min}$. The results are shown in Figure 4.

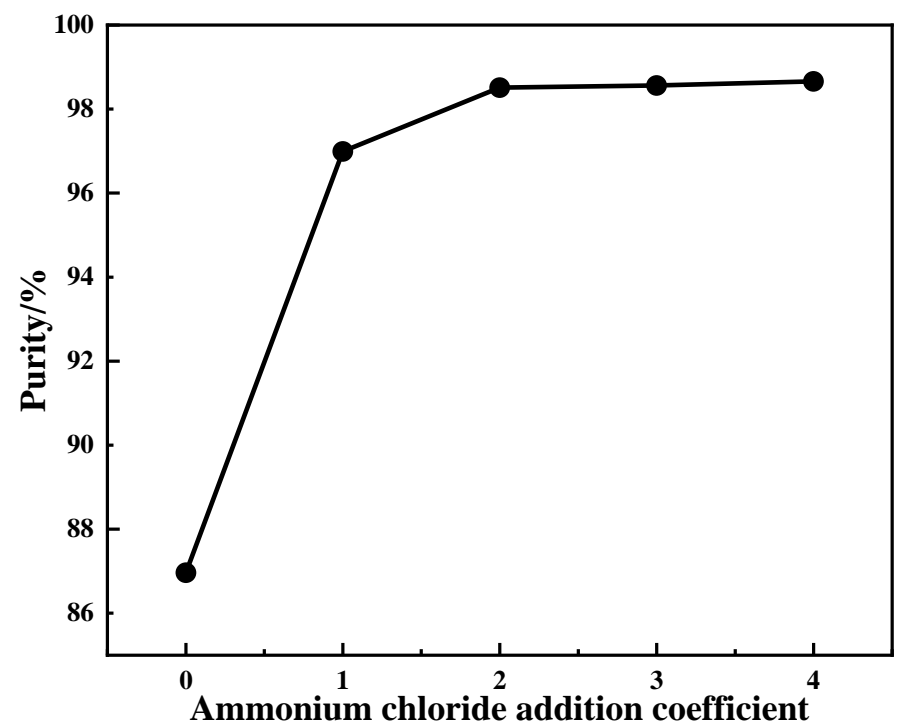

Figure 4. Effect of ammonium addition coefficient on product purity.

Figure 4 indicates that the purity of the purified product increased with the increase in ammonium addition coefficient. Compared with the hydrolyzed vanadium precipitation product, its purity showed a significant improvement through the ammonium chloride purification. When the ammonium addition coefficient was greater than 2 , the purity of the purified product showed no obvious improvement. The product purity was $98.51 \%$ at the 
ammonium addition coefficient of 2 . To reduce the ammonium consumption as much as possible while increasing the purity of the purified product, the best ammonium addition coefficient was 2 .

\subsubsection{Effect of Purification Time on Product Purity}

To investigate the efficiency of the production process, the effect of purification time on the purity of purified products was assessed under the following conditions: purification temperature of $25^{\circ} \mathrm{C}$ with purification performed twice, ammonium addition coefficient of 2. The experimental results are shown in Figure 5.

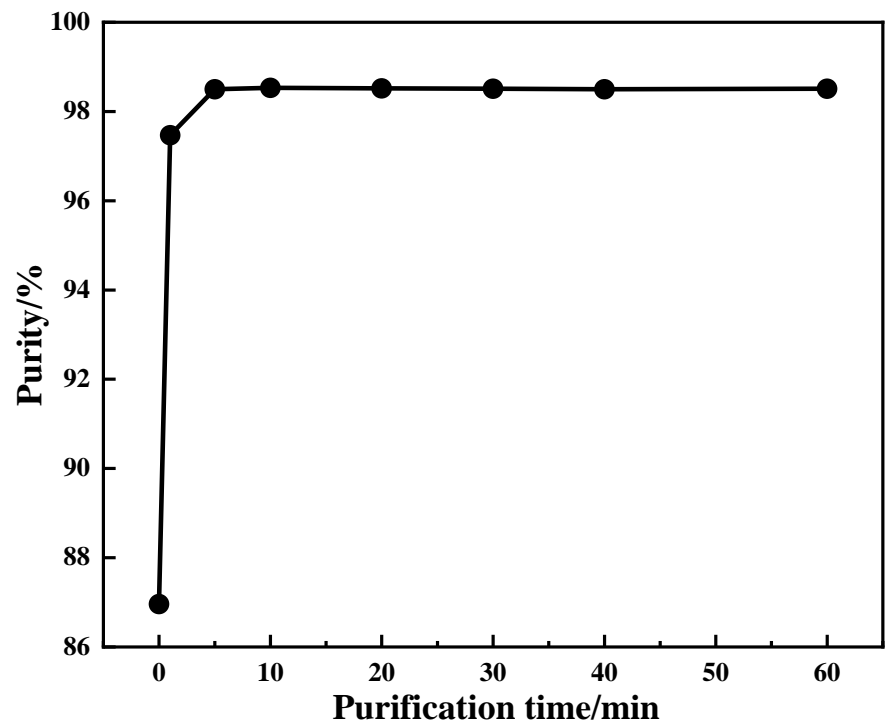

Figure 5. Effect of purification time on product purity.

The improvement in product purity was related to the substitution of ammonium for sodium. It can be seen in Figure 5 that the purity of the purified product increases sharply within 0-5 min, which indicates that the purification reaction of ammoniumsubstituted sodium ions mainly occurs in the first $5 \mathrm{~min}$. After $5 \mathrm{~min}$ of purification, the purity of the purified product tends to be constant with the increase in time, which shows that the substitution reaction between ammonium and sodium ions tends to be balanced. Considering the production efficiency and energy consumption, the optimum purification time was $5 \mathrm{~min}$.

\subsubsection{Effect of Purification Frequency on Product Purity}

To find the best process conditions, the purity of the purified product should be at least $99 \%$. The purification process was carried out from zero to five times without changing the total ammonium consumption under the following conditions: purification temperature of $25{ }^{\circ} \mathrm{C}$, purification time of $5 \mathrm{~min}$, ammonium addition coefficient of 2 . The results are shown in Figure 6.

It can be seen from Figure 6 that the purity of the purified product shows an upward trend with increasing purification frequency increasing. The purity of the purified product increases slowly when the purification frequency exceeds two cycles. This phenomenon indicates that the reaction gradually tends to balance after purification is performed twice. Therefore, to reduce the process flow, improve production efficiency, and reduce energy consumption while ensuring the purity of the purified product, the optimal purification frequency is two cycles. 


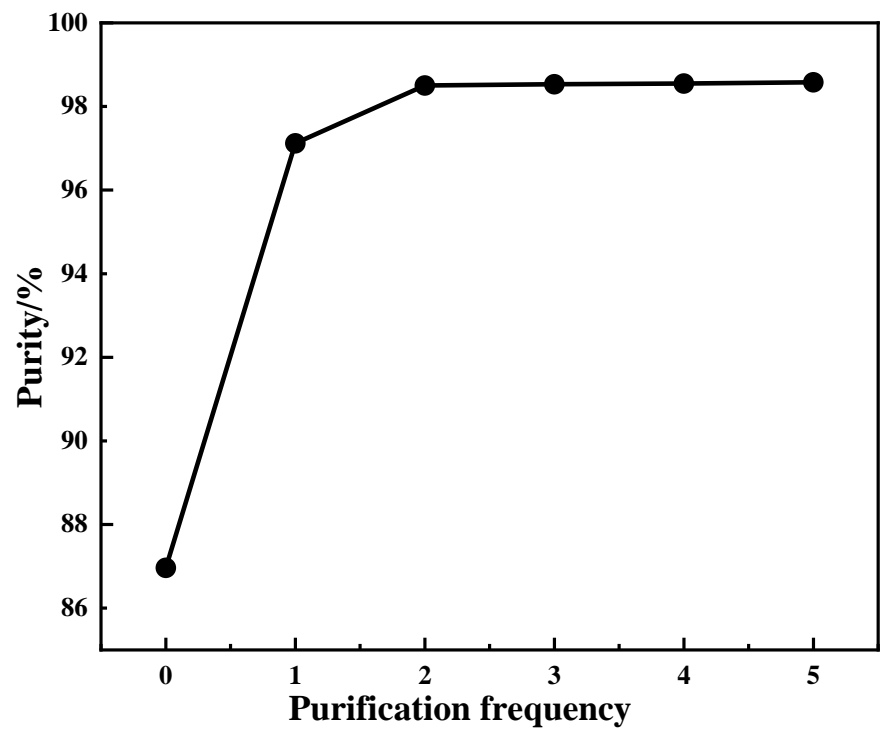

Figure 6. Effect of purification frequency on product purity.

\subsubsection{Effect of Purification Temperature on Product Purity}

A series of purification tests of the influence of purification temperature on the purification effect were carried out from $25{ }^{\circ} \mathrm{C}$ to $95{ }^{\circ} \mathrm{C}$ under the following conditions: the purification was performed twice, with a purification time of $5 \mathrm{~min}$ and ammonium addition coefficient of 2 . The results are shown in Figure 7.

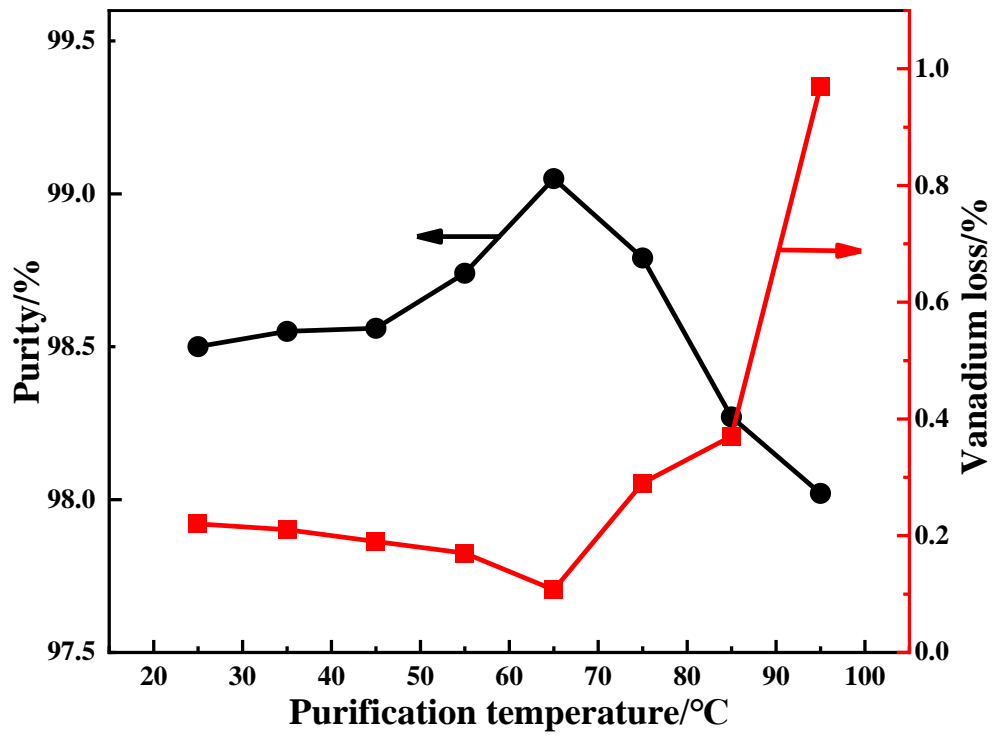

Figure 7. Effect of purification temperature on product purity.

It can be seen in Figure 7 that the purification temperature has a significant effect on the purity of the purified product. As the purification temperature gradually increases from $25{ }^{\circ} \mathrm{C}$ to $95{ }^{\circ} \mathrm{C}$, vanadium loss first decreases, then increases. The purity of the purified product shows a trend of rising first and then falling. At the purification temperature of $65{ }^{\circ} \mathrm{C}$, the product reaches a maximum of $99.05 \%$. The replacement of $\mathrm{Na}^{+}$with $\mathrm{NH}_{4}{ }^{+}$is easy due to the temperature rises [19]. The binding capacity of $\mathrm{NH}_{4}{ }^{+}$with polyvanadate is greater than $\mathrm{Na}^{+}$[12]. Therefore, the $\mathrm{V}_{2} \mathrm{O}_{5}$ purity of purified product will be increased and the vanadium loss will be reduced when the temperature is increased from $25^{\circ} \mathrm{C}$ to $65^{\circ} \mathrm{C}$. After the temperature exceeds $65^{\circ} \mathrm{C}$, vanadium loss increases sharply. The dissolution of ammonium polyvanadate will affect the $\mathrm{V}_{2} \mathrm{O}_{5}$ purity of the product [20]. For this reason, $65^{\circ} \mathrm{C}$ is the best purification temperature. 


\subsection{Characterization of $\mathrm{V}_{2} \mathrm{O}_{5}$ Product}

Based on the experiments, the vanadium precipitation efficiency can reach $99.23 \%$ and the purity of purified product can achieve $99.05 \%$ of the value for hydrolytic vanadium precipitation-purification with ammonium salt under the following conditions: time of $1.5 \mathrm{~h}$, temperature of $98^{\circ} \mathrm{C}$, initial $\mathrm{pH}$ of 2 , ammonium addition coefficient of 2 , purification time of $5 \mathrm{~min}$ with purification performed twice, purification temperature of $65^{\circ} \mathrm{C}$. The purified product was calcined at $520^{\circ} \mathrm{C}\left(\mathrm{V}_{2} \mathrm{O}_{5}\right.$ product), and the composition of the $\mathrm{V}_{2} \mathrm{O}_{5}$ product is shown in Table 2 and Figure 8.

Table 2. Chemical composition of $\mathrm{V}_{2} \mathrm{O}_{5}$ sample (\%).

\begin{tabular}{cccccccc}
\hline Item & $\mathbf{V}_{\mathbf{2}} \mathbf{O}_{\mathbf{5}}$ & $\mathbf{S i}$ & $\mathbf{F e}$ & $\mathbf{P}$ & $\mathbf{S}$ & $\mathbf{A s}$ & $\mathbf{N a}_{\mathbf{2}} \mathbf{O}+\mathbf{K}_{\mathbf{2}} \mathbf{O}$ \\
\hline $\mathrm{V}_{2} \mathrm{O}_{5}$ sample & 99.05 & $<0.01$ & 0.075 & 0.026 & 0.01 & $<0.01$ & 0.74 \\
Standard sample & $\geq 99.00$ & $\leq 0.08$ & $\leq 0.08$ & $\leq 0.03$ & $\leq 0.08$ & $\leq 0.01$ & $\leq 0.8$ \\
\hline
\end{tabular}

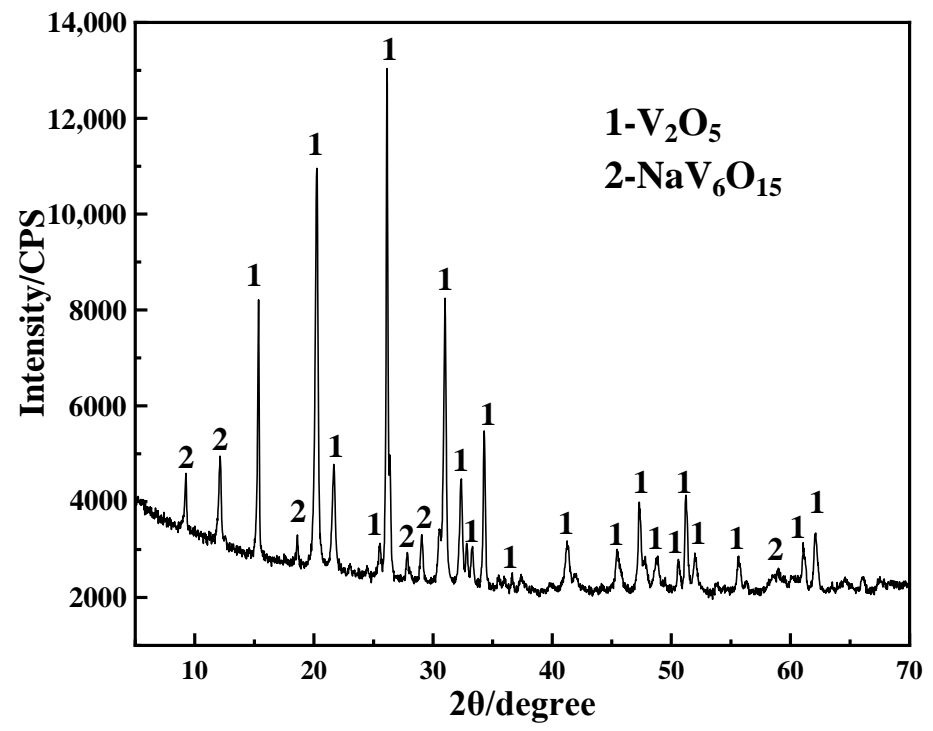

Figure 8. XRD spectra of $\mathrm{V}_{2} \mathrm{O}_{5}$ samples.

It can be seen from Figure 8 that the main components of the $\mathrm{V}_{2} \mathrm{O}_{5}$ product are $\mathrm{V}_{2} \mathrm{O}_{5}$ and $\mathrm{NaV}_{6} \mathrm{O}_{15}$. Less miscellaneous peaks of $\mathrm{V}_{2} \mathrm{O}_{5}$ indicate high product purity. Table 2 shows that the content of impurity ions in the $\mathrm{V}_{2} \mathrm{O}_{5}$ product meets the requirements for grade 99 vanadium pentoxide outlined in standard $\mathrm{YB} / \mathrm{T}$ 5304-2017. Therefore, $\mathrm{V}_{2} \mathrm{O}_{5}$ meeting the standard YB/T 5304-2017 can be successfully prepared via hydrolytic vanadium precipitation-purification using the ammonium salt experimental process.

\subsection{Comparison of Vanadium Preparation Processes}

The general ammonium salt vanadium precipitation process and ammonia spirit precipitation vanadium process were used to perform a test with the vanadium-rich solution in this system under the following conditions: initial $\mathrm{pH}$ of 2, time of $1.5 \mathrm{~h}$, and temperature of $98^{\circ} \mathrm{C}$. The experimental results are shown in Table 3.

Table 3. Comparison of different vanadium precipitation processes.

\begin{tabular}{cccc}
\hline Item & $\begin{array}{c}\text { Precipitation by } \\
\mathbf{N H}_{\mathbf{3}} \cdot \mathbf{H}_{\mathbf{2}} \mathbf{O}\end{array}$ & $\begin{array}{c}\text { Precipitation by } \\
\mathbf{N H}_{\mathbf{4}} \mathbf{C l}\end{array}$ & $\begin{array}{c}\text { Purification by } \\
\mathbf{N H}_{\mathbf{4}} \mathbf{C l}\end{array}$ \\
\hline $\mathrm{K}$ & 9.9 & 10 & 2.0 \\
efficiency & $99.41 \%$ & $99.12 \%$ & $99.23 \%$ \\
purity & $98.35 \%$ & $98.04 \%$ & $99.05 \%$ \\
\hline
\end{tabular}


It can be seen from Table 3 that the vanadium precipitation efficiency reached $99.41 \%$, and the product purity was $98.35 \%$ at the ammonium coefficient of $K=9.9$ during the ammonia spirit precipitation vanadium process. The ammonium consumption of the hydrolytic vanadium precipitation-purification process with ammonium salt was reduced by $79.80 \%$, and the product purity was increased by $0.70 \%$ compared with the ammonia spirit precipitation vanadium process. The vanadium precipitation efficiency was $99.12 \%$ and the product purity was $98.04 \%$ at $\mathrm{K}=10$ during ammonium chloride vanadium precipitation. The ammonium consumption of the new combined process was reduced by $80.00 \%$, and the product purity was increased by $1.01 \%$ compared with the ammonia chloride precipitation vanadium process. The combined process successfully reduced the ammonium consumption, while ensuring the purity of the product and reducing the environmental pollution of ammonia nitrogen.

\subsection{Composition and Structure of Purified Products}

The transformation of the product composition during the purification process was determined by comparing the phase compositions of the unpurified product (hydrolyzed vanadium precipitation product) and the purified product. Because Al and other impurity ions will affect the crystallization of polyvanadate [14], the compositions of the unpurified product and the purified product were determined using a vanadium-rich solution containing only vanadium (no other impurity ions) to carry out the hydrolytic vanadium precipitation-ammonium salt purification test under the same conditions. The XRD patterns of the unpurified product and purified product obtained under the optimal vanadium precipitation conditions are shown in Figure 9.
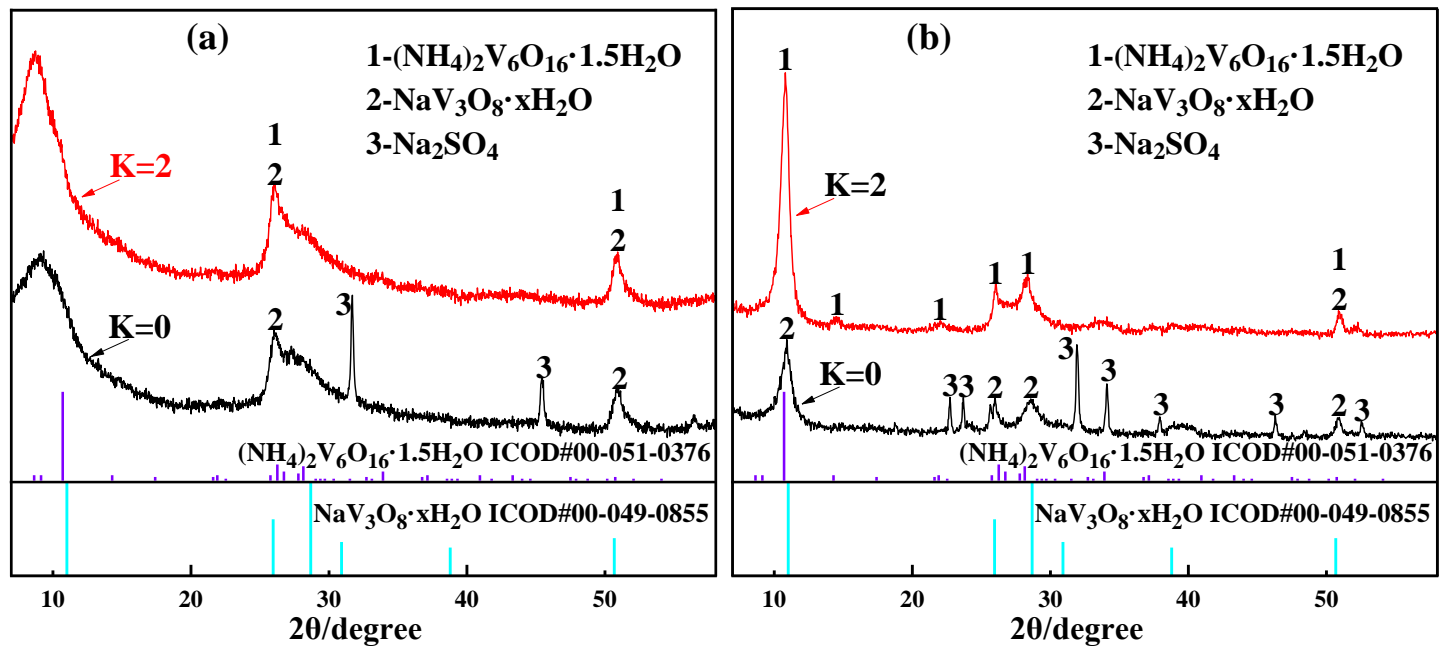

Figure 9. (a) XRD spectrum of the product prepared using the vanadium-rich solution containing impurity ions. (b) XRD spectrum of the product prepared using the vanadium-rich solution without impurity ions ( $\mathrm{K}=0$ - unpurified product; $\mathrm{K}=2$-purified product).

A comparison between Figure 9a,b illustrates that amorphous impurity Al ions seriously affect the peak shape of the product. The appearance of the dispersion peak indicates that the crystallinity of vanadium precipitation is not high. Combined with the properties of the vanadium-rich liquid, $\mathrm{Al}$ and $\mathrm{Na}$ in the precipitation process will reduce the crystallinity of precipitation [12]. Figure $9 \mathrm{~b}$ proves that the diffraction peaks of the unpurified products $(\mathrm{K}=0)$ correspond to standard peaks of $\mathrm{NaV}_{3} \mathrm{O}_{8} \cdot \mathrm{xH}_{2} \mathrm{O}$ (ICOD\#00-049-0855). Therefore, the unpurified product $(\mathrm{K}=0)$ comprises $\mathrm{NaV}_{3} \mathrm{O}_{8} \cdot \mathrm{xH}_{2} \mathrm{O}$ and $\mathrm{Na}_{2} \mathrm{SO}_{4}$. The excessive sodium content in the crystallized product leads to low purity of the vanadium precipitation product. The diffraction peaks of the purified product $(\mathrm{K}=2)$ correspond to standard peaks of $\left(\mathrm{NH}_{4}\right)_{2} \mathrm{~V}_{6} \mathrm{O}_{16} \cdot 1.5 \mathrm{H}_{2} \mathrm{O}$ (ICOD\#00-051-0376). It can be inferred that the 
ammonium in the liquid phase enters the purified product. The crystal $\mathrm{NaV}_{3} \mathrm{O}_{8} \cdot \mathrm{xH}_{2} \mathrm{O}$ is transformed into $\left(\mathrm{NH}_{4}\right)_{2} \mathrm{~V}_{6} \mathrm{O}_{16} \cdot 1.5 \mathrm{H}_{2} \mathrm{O}$ crystal during the purification process.

To further determine the composition of the product, thermogravimetric analysis (TGA) and derivative thermogravimetry (DTG) analyses were performed to further investigate the presence of the product. The results are shown in Figure 10.
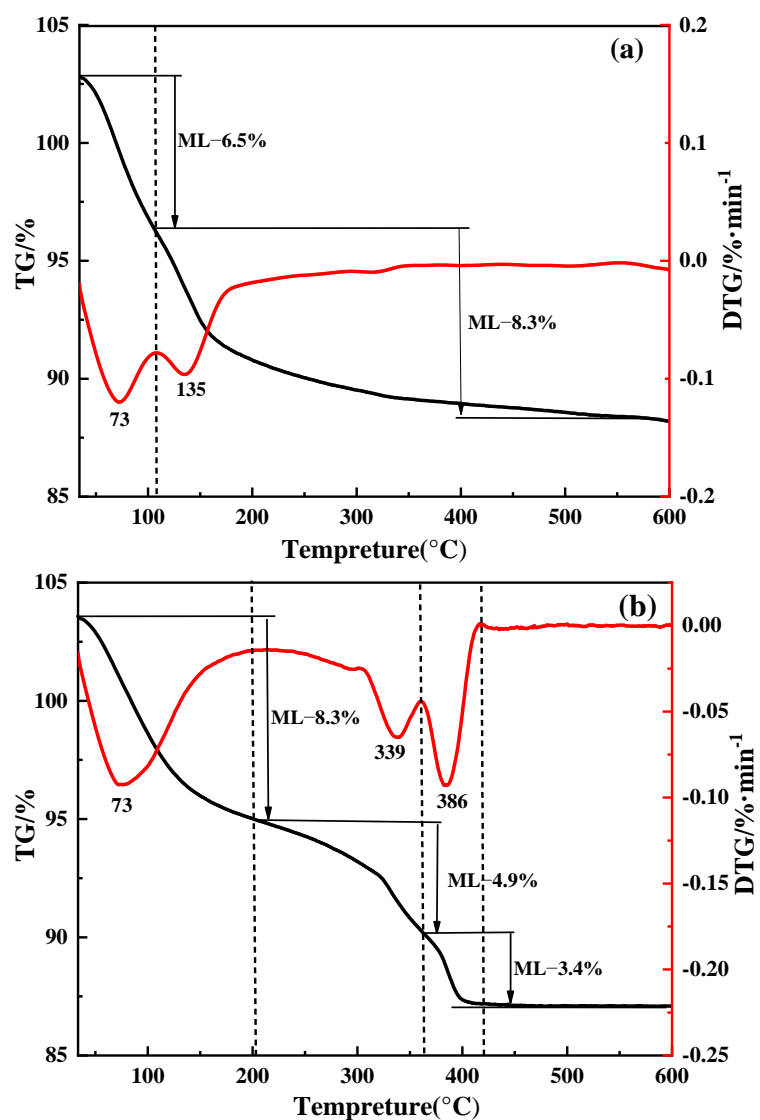

Figure 10. TGA and DTG analyses of purified and unpurified products under nitrogen atmosphere: (a) unpurified product; (b) purified product.

Figure 10a shows the two weight loss ranges of unpurified products. The first weight loss range was from 34 to $108{ }^{\circ} \mathrm{C}$, and the second weight loss was from 108 to $600{ }^{\circ} \mathrm{C}$ [21]. The thermal decomposition rate reached its maximum at $73^{\circ} \mathrm{C}$ and $135^{\circ} \mathrm{C}$. The first weight loss of $\approx 6.5 \%$ for unpurified products corresponded to the evaporation of water. The second weight loss of $\approx 8.3 \%$ occurred due to the departure of structural water, which was intercalated between the vanadate layers. One can calculate that $\mathrm{NaV}_{3} \mathrm{O}_{8} \cdot \mathrm{xH}_{2} \mathrm{O}$ crystal contains 1.5 times the amount of crystal water by calculating the weight loss in the second stage. Therefore, the chemical formula for the unwashed products can be determined as $\mathrm{NaV}_{3} \mathrm{O}_{8} \cdot 1.5 \mathrm{H}_{2} \mathrm{O}$. Figure $10 \mathrm{~b}$ indicates the three weight loss ranges of purified product. The thermal decomposition rates reach their maximum values at $73^{\circ} \mathrm{C}, 339^{\circ} \mathrm{C}$, and $386{ }^{\circ} \mathrm{C}$, respectfully. The first weight loss of $\approx 8.3 \%$ from 34 to $207^{\circ} \mathrm{C}$ for purified product corresponded to the evaporation of weakly adsorbed structural water [22]. The second weight loss of $\approx 4.9 \%$ from 207 to $360{ }^{\circ} \mathrm{C}$ was attributed to the decomposition of $\left(\mathrm{NH}_{4}\right)_{2} \mathrm{~V}_{6} \mathrm{O}_{16} \cdot 1.5 \mathrm{H}_{2} \mathrm{O}$ and the third weight loss of $\approx 3.4 \%$ from 360 to $408^{\circ} \mathrm{C}$ corresponded to the deintercalation of strongly bound $\mathrm{H}_{2} \mathrm{O}$ via Equation (3) [18,23]. It can be determined that the composition of the unpurified product is $\mathrm{NaV}_{3} \mathrm{O}_{8} \cdot 1.5 \mathrm{H}_{2} \mathrm{O}$ and the purified product is $\left(\mathrm{NH}_{4}\right)_{2} \mathrm{~V}_{6} \mathrm{O}_{16} \cdot 1.5 \mathrm{H}_{2} \mathrm{O}$. The component of the purified product is $\left(\mathrm{NH}_{4}\right)_{2} \mathrm{~V}_{6} \mathrm{O}_{16} \cdot 1.5 \mathrm{H}_{2} \mathrm{O}$ as indicated by the literature comparison. The results of TG and XRD analyses are consistent:

$$
\left(\mathrm{NH}_{4}\right)_{2} \mathrm{~V}_{6} \mathrm{O}_{16} \cdot 1.5 \mathrm{H}_{2} \mathrm{O} \rightarrow 3 \mathrm{~V}_{2} \mathrm{O}_{5}+2 \mathrm{NH}_{3} \uparrow+2.5 \mathrm{H}_{2} \mathrm{O}
$$


Through phase and thermogravimetric analyses, chemical reactions related to $\mathrm{NH}_{4}^{+}$ during the purification process were identified. $\mathrm{NH}_{4}{ }^{+}$in the liquid phase enters the purified product and exists as $\left(\mathrm{NH}_{4}\right)_{2} \mathrm{~V}_{6} \mathrm{O}_{16} \cdot 1.5 \mathrm{H}_{2} \mathrm{O}$ crystals. To evidence the chemical changes and reveal the mechanism of $\mathrm{NH}_{4}{ }^{+}$in the purification process, the products with ammonium addition coefficients of $\mathrm{K}=0$ (unpurified product) and $\mathrm{K}=2$ (purified product) were analyzed via FTIR. The analysis results are shown in Figure 11.

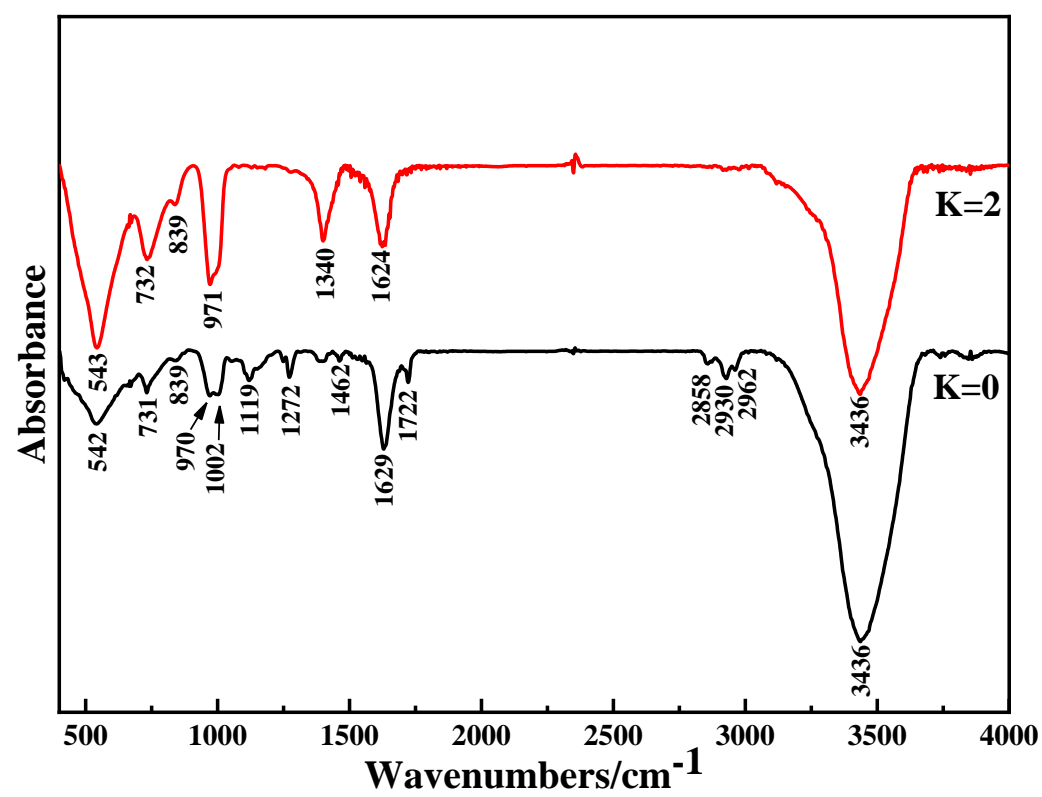

Figure 11. FTIR spectra of unpurified and purified products ( $\mathrm{K}=0$-unpurified product; $\mathrm{K}=2$-purified product).

It can be seen from Figure 11 that the peaks at $542 \mathrm{~cm}^{-1}$ and $543 \mathrm{~cm}^{-1}$ are attributed to symmetric stretching vibration of $\mathrm{V}-\mathrm{O}-\mathrm{V}[24,25]$, while the peaks at $731 \mathrm{csm}^{-1}$ and $732 \mathrm{~cm}^{-1}$ correspond to the asymmetric $\mathrm{V}-\mathrm{O}-\mathrm{V}$ bending mode $[26,27]$. The characteristic peaks of the two types of $\mathrm{V}-\mathrm{O}-\mathrm{V}$ are shifted from low to high peaks after the purification process, which means that the intervention of $\mathrm{NH}_{4}{ }^{+}$will influence the structure of the $\mathrm{NaV}_{3} \mathrm{O}_{8} \cdot 1.5 \mathrm{H}_{2} \mathrm{O}$ crystal. The $\mathrm{V}_{3} \mathrm{O}_{8}{ }^{-}$layers exist due to the peak at $839 \mathrm{~cm}^{-1}$ being assigned to the symmetric stretching mode of the $\mathrm{VO}_{6}$ [28]. The double peak of the terminal $\mathrm{V}=\mathrm{O}$ bond at $970 \mathrm{~cm}^{-1}$ and $1002 \mathrm{~cm}^{-1}$ disappears [29,30], and turns into a single peak of the $\mathrm{V}-\mathrm{O}-\mathrm{V}$ bond at $971 \mathrm{~cm}^{-1}$ [31], which illustrates that the two $\mathrm{V}_{3} \mathrm{O}_{8}{ }^{-}$layers will be combined end-to-end and form a $\mathrm{V}_{6} \mathrm{O}_{16}{ }^{2-}$ layer. The peak at $1400 \mathrm{~cm}^{-1}$ could be ascribed to $\mathrm{NH}_{4}{ }^{+}$bending vibration absorption, which could prove that $\mathrm{NH}_{4}{ }^{+}$exists in the purified product as $\left(\mathrm{NH}_{4}\right)_{2} \mathrm{~V}_{6} \mathrm{O}_{16} \cdot 1.5 \mathrm{H}_{2} \mathrm{O}$ crystals [32].

\section{Crystal Purification Mechanism}

The phase analysis shows that the $\mathrm{NaV}_{3} \mathrm{O}_{8} \cdot 1.5 \mathrm{H}_{2} \mathrm{O}$ crystal is a layered compound [33]. The $\mathrm{V}_{3} \mathrm{O}_{8}{ }^{-}$layer of $\mathrm{NaV}_{3} \mathrm{O}_{8} \cdot 1.5 \mathrm{H}_{2} \mathrm{O}$ crystal is composed of $\mathrm{VO}_{6}$ octahedrons and $\mathrm{VO}_{5}$ square pyramids sharing a vertex oxygen atom. $\mathrm{Na}^{+}$is in the interlayer octahedral gap of $\mathrm{V}_{3} \mathrm{O}_{8}{ }^{-}$layers. The layer spacing $\left(\mathrm{d}_{1}\right)$ of the $\mathrm{V}_{3} \mathrm{O}_{8}{ }^{-}$layer is $7.08 \AA$ [34]. The positively charged $\mathrm{Na}^{+}$and the $\mathrm{V}_{3} \mathrm{O}_{8}$ - layer are combined by electrostatic force [35]. The structure of $\left(\mathrm{NH}_{4}\right)_{2} \mathrm{~V}_{6} \mathrm{O}_{16} \cdot 1.5 \mathrm{H}_{2} \mathrm{O}$ crystal is similar to $\mathrm{NaV}_{3} \mathrm{O}_{8} \cdot 1.5 \mathrm{H}_{2} \mathrm{O}$ crystal. The layer spacing $\left(\mathrm{d}_{2}\right)$ of the $\mathrm{V}_{6} \mathrm{O}_{16}{ }^{-}$layer is $8.191 \AA$ [36]. The hydrogen atoms in $\mathrm{NH}_{4}{ }^{+}$combine with adjacent oxygen atoms of the $\mathrm{V}_{6} \mathrm{O}_{16}$ - layer via the hydrogen bond [37].

Combining the experimental phenomena and analyses shows that the purification process probably includes the replacement of $\mathrm{Na}^{+}$with $\mathrm{NH}_{4}{ }^{+}$and the polymerization of $\mathrm{V}_{3} \mathrm{O}_{8}{ }^{-}$into $\mathrm{V}_{6} \mathrm{O}_{16}{ }^{2-}$. The structures of the $\mathrm{NaV}_{3} \mathrm{O}_{8}$ crystal and $\left(\mathrm{NH}_{4}\right)_{2} \mathrm{~V}_{6} \mathrm{O}_{16}$ crystals are 
used to describe the transformation mechanism of the purification process. The probable mechanism of the purification process is shown in Figure 12.
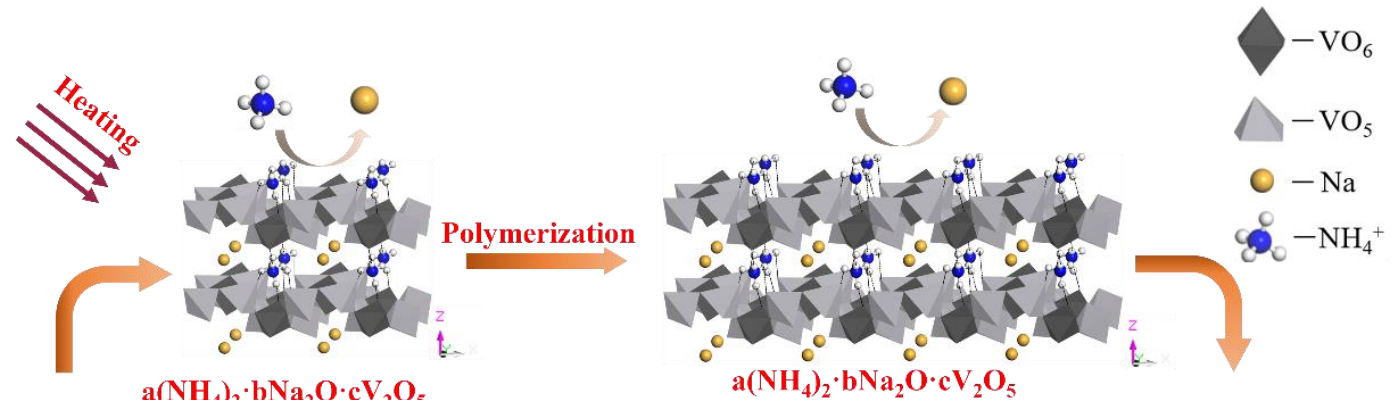

$\mathrm{a}\left(\mathrm{NH}_{4}\right)_{2} \cdot \mathrm{bNa}_{2} \mathrm{O} \cdot \mathrm{cV} \mathrm{O}_{5}$
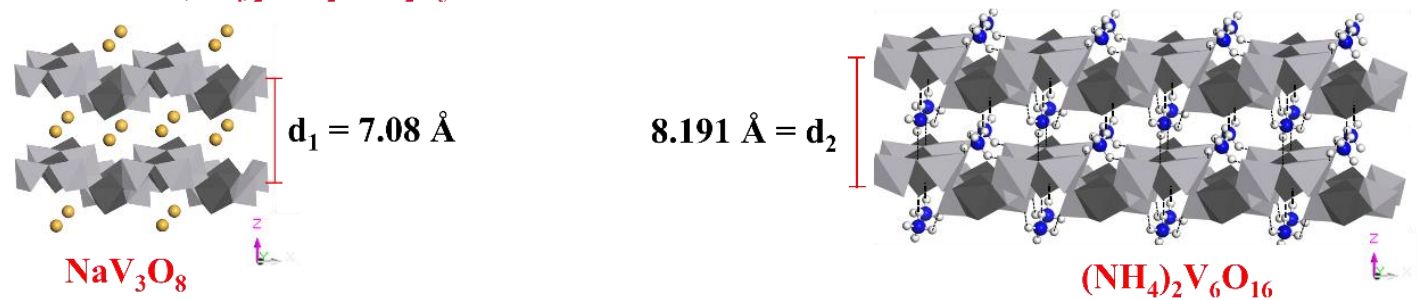

Figure 12. Schematic diagram of the probable mechanism of the purification process.

The probable mechanism of the purification process is shown in Figure 12. The entire purification process mainly involves three phases. Firstly, the $\mathrm{V}_{3} \mathrm{O}_{8}$ - layer spacing of $\mathrm{NaV}_{3} \mathrm{O}_{8} \cdot 1.5 \mathrm{H}_{2} \mathrm{O}$ crystals will expand via heating [38]. The binding capacity of $\mathrm{NH}_{4}^{+}$and polyvanadate is greater than $\mathrm{Na}^{+}$[12], which will make the diffusion and migration of $\mathrm{NH}_{4}{ }^{+}$ in the $\mathrm{V}_{3} \mathrm{O}_{8}{ }^{-}$layer easier [19]. Secondly, $\mathrm{NH}_{4}{ }^{+}$will attack the $\mathrm{Na}^{+}$of the $\mathrm{NaV}_{3} \mathrm{O}_{8} \cdot 1.5 \mathrm{H}_{2} \mathrm{O}$ crystal after the intervention of $\mathrm{NH}_{4}{ }^{+}$. The electrostatic combination of $\mathrm{Na}^{+}$with the $\mathrm{V}_{3} \mathrm{O}_{8}{ }^{-}$ layer will be destroyed. $\mathrm{NH}_{4}{ }^{+}$will replace $\mathrm{Na}^{+}$in the octahedral vacancy in the $\mathrm{V}_{3} \mathrm{O}_{8}{ }^{-}$ layer [35]. The intermediate product $\left(\mathrm{a}\left(\mathrm{NH}_{4}\right)_{2} \cdot \mathrm{bNa}{ }_{2} \mathrm{O} \cdot \mathrm{cV}_{2} \mathrm{O}_{5}\right.$, where $\mathrm{a}, \mathrm{b}$, and c are related to reaction conditions) is a kind of crystal that includes $\mathrm{Na}^{+}$and $\mathrm{NH}_{4}^{+}$[14]. The hydrogen atoms in $\mathrm{NH}_{4}{ }^{+}$will combine with adjacent oxygen atoms on the $\mathrm{V}_{3} \mathrm{O}_{8}{ }^{-}$layer through intermolecular hydrogen bonds [39]. Finally, the $\mathrm{pH}$ of $20 \mathrm{~g} / \mathrm{L}$ ammonium chloride solution is 4.23. The aggregated state of vanadium mainly exists in the form of $\mathrm{V}_{6} \mathrm{O}_{16}{ }^{2-}$ in the $\mathrm{pH}$ range of 2.2-5.0 [40]. The destruction of that layered structure also creates conditions for polymerization. Therefore, the polymerization of $\mathrm{V}_{3} \mathrm{O}_{8}{ }^{-}$to $\mathrm{V}_{6} \mathrm{O}_{16}{ }^{2-}$ occurred. The most stable $\left(\mathrm{NH}_{4}\right)_{2} \mathrm{~V}_{6} \mathrm{O}_{16} \cdot 1.5 \mathrm{H}_{2} \mathrm{O}$ crystal was formed through continuous replacement reaction and polymerization reaction.

\section{Conclusions}

(1) During the hydrolytic vanadium precipitation-purification process with ammonium salt, $99.23 \%$ vanadium precipitation efficiency and $99.05 \% \mathrm{~V}_{2} \mathrm{O}_{5}$ purity can be achieved under the following conditions: time of $1.5 \mathrm{~h}$, temperature of $98{ }^{\circ} \mathrm{C}$, initial $\mathrm{pH}$ of 2 , ammonium addition coefficient of 2 , purification time of 5 min with purification performed twice, purification temperature of $65^{\circ} \mathrm{C}$. The purity of the purified product meets the standard YB/T 5304-2017.

(2) The ammonium consumption during the hydrolytic vanadium precipitationpurification process with ammonium salt was reduced by $79.80 \%$ compared with the ammonia spirit vanadium precipitation process and reduced by $80.00 \%$ compared with the ammonium chloride vanadium precipitation process. While the combined process reduces ammonium consumption, the purity of vanadium products is improved to above $99.05 \%$. The process reduces the generation of ammonia nitrogen wastewater and makes the preparation of $\mathrm{V}_{2} \mathrm{O}_{5}$ more environmentally friendly.

(3) The mechanism of the ammonium salt purification process was revealed. The purification process can be divided into three reaction stages. First, the $\mathrm{V}_{3} \mathrm{O}_{8}{ }^{-}$layers of 
sodium vanadate crystal is enlarged via heating and the attack of $\mathrm{NH}_{4}{ }^{+}$, which make it easier for the $\mathrm{NH}_{4}{ }^{+}$to diffuse into the $\mathrm{V}_{3} \mathrm{O}_{8}{ }^{-}$layer. Secondly, $\mathrm{NH}_{4}{ }^{+}$destroys the electrostatic bond between $\mathrm{Na}+$ with the $\mathrm{V}_{3} \mathrm{O}_{8}{ }^{-}$layer and replaces the $\mathrm{Na}^{+}$in the octahedral vacancy of the $\mathrm{V}_{3} \mathrm{O}_{8}{ }^{-}$layer. Finally, the polymerization of $\mathrm{V}_{3} \mathrm{O}_{8}{ }^{-}$to $\mathrm{V}_{6} \mathrm{O}_{16}{ }^{2-}$ occurs due to the aggregated state of vanadium mainly existing in the form of $\mathrm{V}_{6} \mathrm{O}_{16}{ }^{2-}$ in the $\mathrm{pH}$ range of 2.2-5.0.

Author Contributions: Conceptualization, J.H. and Y.Z.; methodology, P.H.; software, J.H.; validation, J.H. and Y.Z.; formal analysis, G.L. and P.H.; investigation, G.L.; resources, J.H.; data curation, P.H.; writing-original draft preparation, G.L.; writing-review and editing, G.L.; visualization, J.H.; supervision, J.H. and Y.Z.; project administration, J.H.; funding acquisition, J.H. All authors have read and agreed to the published version of the manuscript.

Funding: This research was funded by National Key R\&D Program of China (2020YFC1909702) and Project of National Natural Science Foundation of China (No. 51974207).

Institutional Review Board Statement: Not applicable.

Informed Consent Statement: Not applicable.

Data Availability Statement: No new data were created or analyzed in this study. Data sharing is not applicable to this article.

Conflicts of Interest: The authors declare no conflict of interest.

\section{References}

1. Hu, P.; Zhang, Y. Mechanism of vanadium selective separation from iron in shale under an environmentally friendly oxalate ligand system. Sep. Purif. Technol. 2021, 276, 119269. [CrossRef]

2. Zhang, Y.M.; Bao, S.X.; Liu, T.; Chen, T.J.; Huang, J. The technology of extracting vanadium from stone coal in China: History, current status and future prospects. Hydrometallurgy 2011, 109, 116-124. [CrossRef]

3. Liu, S.; Zhu, H.; Zhang, B.; Li, G.; Zhu, H.; Ren, Y.; Geng, H.; Yang, Y.; Liu, Q.; Li, C.C. Tuning the Kinetics of Zinc-Ion Insertion/Extraction in $\mathrm{V}_{2} \mathrm{O}_{5}$ by In Situ Polyaniline Intercalation Enables Improved Aqueous Zinc-Ion Storage Performance. Adv. Mater. 2020, 32, e2001113. [CrossRef] [PubMed]

4. Zhang, G.; Zhang, Y.; Bao, S.; Huang, J.; Zhang, L. A Novel Eco-Friendly Vanadium Precipitation Method by Hydrothermal Hydrogen Reduction Technology. Minerals 2017, 7, 182. [CrossRef]

5. Zheng, Q.; Zhang, Y.; Liu, T.; Huang, J.; Xue, N.; Shi, Q. Optimal Location of Vanadium in Muscovite and Its Geometrical and Electronic Properties by DFT Calculation. Minerals 2017, 7, 32. [CrossRef]

6. Skyllas Kazacos, M.; Cao, L.; Kazacos, M.; Kausar, N.; Mousa, A. Vanadium Electrolyte Studies for the Vanadium Redox Battery-A Review. ChemSusChem 2016, 9, 1521-1543. [CrossRef]

7. Thangarasu, R.; Kulathuraan, K.; Chang, J.H.; Subramani, S.; Chandar, N.R.; Balasundaram, O.N.; Mohanraj, K.; Shkir, M.; Ali, A.M. Influence of zirconium ions on the key characteristics of $\mathrm{V}_{2} \mathrm{O}_{5}$ nanorods and current-voltage features of the $n-\mathrm{ZrxV}_{2} \mathrm{O}_{5} / \mathrm{p}-\mathrm{Si}$ photodetector. J Mater Sci. Mater Electron 2022, 33, 2932-2948. [CrossRef]

8. Ravinder, G.; Sreelatha, C.J.; Ganesh, V.; Shkir, M.; Anis, M.; Rao, C.R. Thickness-dependent structural, spectral, linear, nonlinear and z-scan optical studies of $\mathrm{V}_{2} \mathrm{O}_{5}$ thin films prepared by a low-cost sol-gel spin coating technique. Mater. Res. Express 2019, 6, 096403. [CrossRef]

9. Ubaidullah, M.; AlEnizi, A.M.; Shaikh, S.; Ghanem, M.A.; Mane, R.S. Waste PET plastic derived ZnO@NMC nanocomposite via MOF-5 construction for hydrogen and oxygen evolution reactions. J. King Saud Univ. Sci. 2020, 32, 2397-2405. [CrossRef]

10. Gilligan, R.; Nikoloski, A.N. The extraction of vanadium from titanomagnetites and other sources. Miner. Eng. 2019, 146, 106106. [CrossRef]

11. Peng, H. A literature review on leaching and recovery of vanadium. J. Environ. Chem. Eng. 2019, 7, 103313. [CrossRef]

12. Xiong, P.; Zhang, Y.; Bao, S.; Huang, J. Precipitation of vanadium using ammonium salt in alkaline and acidic media and the effect of sodium and phosphorus. Hydrometallurgy 2018, 180, 113-120. [CrossRef]

13. Chen, T.; Zhang, Y.; Song, S. Improved extraction of vanadium from a Chinese vanadium-bearing stone coal using a modified roast-leach process. Asia-Pacific J. Chem. Eng. 2009, 5, 778-784. [CrossRef]

14. Zhang, Y.M. Extracting Vanadium from Stone Coal, 1st ed.; Science Press: Beijing, China, 2014; pp. $185-197$.

15. Kang, Q.; Zhang, Y.; Bao, S. An environmentally friendly hydrothermal method of vanadium precipitation with the application of oxalic acid. Hydrometallurgy 2019, 185, 125-132. [CrossRef]

16. F, Z.Y.; Zhang, Y.M.; Liu, T.; Huang, J.; Yang, X.K. Impact of Impurity Ions on Vanadium Precipitation Process of Stripping Solution from Vanadium Extraction of Stone Coal. Chinese J. Rare Metals 2016, 40, 1060-1065.

17. Wang, X.; Wang, H.; Gao, D.; Chen, B.; Meng, Y.; Wang, M. A clean technology to separate and recover vanadium and chromium from chromate solutions. Hydrometallurgy 2018, 177, 94-99. [CrossRef] 
18. Chithaiah, P.; Vijaya kumar, G.; Nagabhushana, G.P.; Nagaraju, G.; Chandrappa, G.T. Synthesis of single crystalline $\left(\mathrm{NH}_{4}\right)_{2} \mathrm{~V}_{6} \mathrm{O}_{16} \cdot 1.5 \mathrm{H}_{2} \mathrm{O}$ nest-like structures. Phys. E Low-Dimens. Syst. Nanostructures 2014, 59, 218-222. [CrossRef]

19. Elias, A.; Abdellah, Z.N.; Villemin, D.; Didi, M.A. Effect of microwave irradiations on the sorption of alkylimidazolium salts on bentonite. Chem. Pap. 2016, 71, 59-65. [CrossRef]

20. Guo, J.K. Preparation of Ammonium Polyvanadate Using High Concentration of Vanadium Solution Containing Sodium. Iron Steel Vanadium Titanium. 2017, 35, 13-20.

21. Zhu, L.; Li, W.; Xie, L.; Yang, Q.; Cao, X. Rod-like $\mathrm{NaV}_{3} \mathrm{O}_{8}$ as cathode materials with high capacity and stability for sodium storage. Chem. Eng. J. 2019, 372, 1056-1065. [CrossRef]

22. Kim, J.; Lee, S.H.; Park, C.; Kim, H.S.; Park, J.H.; Chung, K.I.; Ahn, H. Controlling Vanadate Nanofiber Interlayer via Intercalation with Conducting Polymers: Cathode Material Design for Rechargeable Aqueous Zinc Ion Batteries. Adv. Funct. Mater. 2021, 31, 2100005. [CrossRef]

23. Wang, H.; Ren, Y.; Wang, W.; Huang, X.; Huang, K.; Wang, Y.; Liu, S. $\mathrm{NH}_{4} \mathrm{~V}_{3} \mathrm{O}_{8}$ nanorod as a high performance cathode material for rechargeable Li-ion batteries. J. Power Sources 2012, 199, 315-321. [CrossRef]

24. Harreld, J.; Wong, H.; Dave, B.; Dunn, B.; Nazar, L. Synthesis and properties of polypyrrole-vanadium oxide hybrid aerogels. J. Non-Crystalline Solids 1998, 225, 319-324. [CrossRef]

25. Hou, J.; Zhang, J.; Wang, Z.; Zhang, Z.; Ding, Z. The phase transition of W-doped $\mathrm{VO}_{2}$ nanoparticles synthesized by an improved thermolysis method. J. Nanosci. Nanotechnol. 2013, 13, 1543-1548. [CrossRef]

26. Ksiksi, R.; Abdelkafi Koubaa, Z.; Mlayah Bellalouna, S.; Aissaoui, D.; Marrakchi, N.; Srairi-Abid, N.; Zid, M.F.; Graia, M. Synthesis, structural characterization and antitumoral activity of $\left(\mathrm{NH}_{4}\right)_{4} \mathrm{Li}_{2} \mathrm{~V}_{10} \mathrm{O}_{28} \cdot 10 \mathrm{H}_{2} \mathrm{O}$ compound. J. Mol. Struct. 2020, 1229, 129492. [CrossRef]

27. Gupta, S.; Singh, K. Structural and optical properties of melt quenched barium doped bismuth vanadate. Phys. B Condens. Matter 2013, 431, 89-93. [CrossRef]

28. Lian, Z.; Zhang, J.; Gu, Y.; Wang, T.; Lou, T. Synthesis and crystal structures of two inorganic-organic hybrid vanadium selenites with layered structures: $\left(\mathrm{DABCOH}_{2}\right)\left[\left(\mathrm{VO}_{2}\right)\left(\mathrm{SeO}_{3}\right)\right]_{2} \cdot 1.25 \mathrm{H}_{2} \mathrm{O}$ and $\left(\mathrm{pipeH}_{2}\right)\left[(\mathrm{VO})_{2}\left(\mathrm{C}_{2} \mathrm{O}_{4}\right)\left(\mathrm{SeO}_{3}\right)\right]$. J. Mol. Struct. 2009, 919, 122-127. [CrossRef]

29. Doadrio, A.L.; Sotelo, J.; Fernández Ruano, A. Synthesis and characterization of oxovanadium (IV) dithiocarbamates with pyridine. Quim. Nova 2002, 25, 525-528. [CrossRef]

30. Jin, A.; Chen, W.; Zhu, Q.; Yang, Y.; Volkov, V.L.; Zakharova, G.S. Electrical and electrochemical characterization of poly (ethylene oxide) $/ \mathrm{V}_{2} \mathrm{O}_{5}$ xerogel electrochromic films. Solid State Ion. 2008, 179, 1256-1262. [CrossRef]

31. Rani, B.J.; Ravi, G.; Yuvakkumar, R. Solvothermal optimization of $\mathrm{V}_{2} \mathrm{O}_{5}$ nanostructures for electrochemical energy production. AIP Conf. Proc. 2020, 030619. [CrossRef]

32. Martynova, S.A.; Plyusnin, P.E.; Asanova, T.I.; Asanov, I.P.; Pishchur, D.P.; Korenev, S.V.; Kosheev, S.V.; Floquet, S.; Cadot, E.; Yusenko, K.V. New Exothermal effects in the thermal decomposition of $[\mathrm{IrCl} 6]^{2-}$-containing salts with $\left[\mathrm{M}\left(\mathrm{NH}_{3}\right)_{5} \mathrm{Cl}\right]^{2+}$ cations: $\left[\mathrm{M}\left(\mathrm{NH}_{3}\right)_{5} \mathrm{Cl}\right]\left[\mathrm{IrCl}_{6}\right](\mathrm{M}=\mathrm{Co}, \mathrm{Cr}, \mathrm{Ru}, \mathrm{Rh}, \mathrm{Ir})$ †ł. New J. Chem. 2018, 42, 1762-1770. [CrossRef]

33. Novák, P.; Shklover, V.; Nesper, R. Magnesium Insertion in Vanadium Oxides: A Structural Study. Z. Für Phys. Chem. 1994, 185, 51-68. [CrossRef]

34. Fuentes, G.; Hernández, Y.; Campos, Y.; López, N.; Rojas, M.L.; Peón, E.; Almirall, A.; Delgado, J.A. COMPOSITION INFLUENCE ON PROPERTIES OF ACRYLIC COMPOSITES LOADED WITH SYNTHETIC HYDROXYAPATITE. Lat Am. Appl. Res. 2008, 38, 105-112.

35. Spahr, M.E.; Novák, P.; Scheifele, W.; Haas, O.; Nesper, R. Electrochemistry of Chemically Lithiated $\mathrm{NaV}_{3} \mathrm{O}_{8}$ : $\mathrm{A}_{\text {Positive Electrode }}$ Material for Use in Rechargeable Lithium-Ion Batteries. J. Electrochem. Soc. 1998, 145, 421-427. [CrossRef]

36. Oka, Y.; Yao, T.; Sato, S.; Yamamoto, N. Hydrothermal Synthesis and Crystal Structure of Barium $\mathrm{Hewettite:} \mathrm{BaV}_{6} \mathrm{O}_{16} \cdot \mathrm{nH}_{2} \mathrm{O}$. J. Solid State Chem. 1998, 140, 219-225. [CrossRef]

37. Lin, B.Z.; Liu, S.X. Ammonium trivanadate (V), $\mathrm{NH}_{4} \mathrm{~V}_{3} \mathrm{O}_{8}$. Acta Crystallogr. Sect. C Cryst. Struct. 1999, 55, 1961-1963. [CrossRef]

38. Wang, J. Study on a Strengthened Process and Mechanism of Vanadium Leaching from Shale with Microwave Intervening. PhD Dissertation, Wuhan University of Science and Technology, Wuhan, China, 2018. Available online: https://kns.cnki.net/KCMS/ detail/detail.aspx?dbname=CDFDLAST2019\&filename=1019068807.nh (accessed on 19 January 2022).

39. Wei, L.; Lian, R.; Wang, D.; Zhao, Y.; Yang, D.; Zhao, H.; Wang, Y.; Chen, G.; Wei, Y. Magnesium Ion Storage Properties in a Layered (NH4)2V6O16·1.5H2O Nanobelt Cathode Material Activated by Lattice Water. ACS Appl. Mater. Interfaces 2021, 13, 30625-30632. [CrossRef]

40. Fu, Z.Y.; Zhang, Y.M.; Liu, T.; Huang, J.; Shi, Q.H.; Zhang, G.B. Vanadium Precipitation with Acidic Ammonium Salt of Stripping Solution from One-Step Vanadium Extraction of Stone Coal. Chin. J. Rare Met. 2015, 39, 462-467. 